\title{
Både krybbedøde og søsken er intrauterint veksthemmet
}

\author{
Nina Øyen ${ }^{1,2}$, Rolv Skjærven ${ }^{2}$, Ruth E. Little ${ }^{3}$ og Allen J. Wilcox ${ }^{3}$ \\ 1. Medisinsk fødselsregister, Universitetet i Bergen \\ 2. Seksjon for medisinsk informatikk og statistikk, Universitetet $i$ Bergen \\ 3. Epidemiology Branch, National Institute of Environmental Health Science, Research Triangle Park, North Carolina, USA \\ Korrespondanse til: Nina Øyen, Seksjon for forebyggende medisin, Institutt for samfunnsmedisinske fag, Universitetet i Bergen, \\ Armauer Hansens hus, 5021 Haukeland sykehus \\ Telefon: 55974661 Telefaks: 55974964 \\ Studien er tidligere publisert og er gjengitt forkortet og med tillatelse fra American Journal of Epidemiology: Øyen N, Skjærven R, Little RE, \\ Wilcox AJ. Fetal growth retardation in sudden infant death (SIDS) babies and their siblings. Am J Epidemiol 1995; 142: 84-90.
}

\section{SAMMENDRAG}

Bakgrunn: Vi undersøkte det intrauterine vekstpotensialet hos barn som senere døde i krybbedød, ved å sammenligne krybbedøde med søsken som overlevde første leveår. Krybbedøde og resten av søskenflokken ble også sammenlignet med søskenflokker uten spedbarnsdødsfall.

Materiale og Metode: Medisinsk fødselsregister registrerte 1,3 millioner fødte og 1984 krybbedøde i 1967-88. Alle fødte ble koblet sammen til søskenflokker. Gjennomsnittlig fødselsvekt og svangerskapslengde ble regnet for krybbedøde, deres søsken og barn i søskenflokker uten dødsfall. Fødselsvekten ble også standardisert for å justere for svangerskapslengde.

Resultater: Mødre med barn som senere døde, fødte lettere barn, i gjennomsnitt 85 g lettere enn søsken og 164 g lettere enn spedbarn i søskenflokker uten dødsfall. Etter at fødselsvekten ble justert for svangerskapslengde, forsvant omtrent hele differansen mellom krybbedøde og søsken, fordi krybbedøde hadde kortere svangerskapslengde. Imidlertid besto differansen mellom krybbedødes søsken og barn i søskenflokker uten dødsfall.

Konklusjon: Krybbedøde, samt deres overlevende søsken er intrauterint veksthemmet. Dette kan skyldes faktorer som bidrar til krybbedød (røyking). Derimot, for tidlig fødsel av barn som senere døde, kan tyde på at svangerskapsrelaterte faktorer virker særskilt på disse barna og ikke på deres søsken.

\section{Øyen N, Skjærven R, Little RE, Wilcox AJ. Fetal growth retardation in sudden infant death (SIDS) babies} and their siblings. Nor J Epidemiol 1997; 7 (1): 49-54.

\section{ENGLISH SUMMARY}

Background: To evaluate the intrauterine growth potential of infants that die from sudden infant death syndrome (SIDS), the authors compared SIDS infants to their surviving siblings. The SIDS sibships themselves were also compared to sibships where all infants survived.

Material and Methods: Data from the population-based Medical Birth Registry of Norway, with 1.3 million births during 1967-1988 were used. From the birth cohorts, 1,984 SIDS cases were identified. All births were linked into sibships. Mean birth weight and gestational age were calculated across sibships of different sizes for first to fourth birth order. In a further analysis, birth weights were standardized to adjust for gestational age.

Results: Mothers of SIDS babies gave birth to smaller babies in general. SIDS babies were on average $85 \mathrm{~g}$ less at birth than their siblings, and $164 \mathrm{~g}$ less compared to babies in non-affected sibships. When birth weights were standardized for gestational age, most of the weight difference between SIDS babies and siblings was due to a shorter gestational age of SIDS babies, while the difference between surviving siblings of SIDS babies and births from non-affected sibships remained.

Conclusion: All births in sibships with a SIDS baby were intrauterine growth retarded. This may reflect factors that contribute to SIDS risk (such as maternal smoking). The factors that contribute to shorter gestational age and further slowing of growth in the SIDS babies, may specifically influence the SIDS baby and not its siblings. 
Årsaken til krybbedød er fortsatt ukjent. Flere studier foreslår at krybbedøde har hatt ugunstige vilkår i mors liv (1-8). Krybbedøde er gjennomsnittlig mindre ved fødselen enn andre barn. Intrauterin veksthemning er ikke årsaken til dødsfallet, men kan være en markør på at fosteret har vært utsatt for et traume som gjør dem spesielt sårbare for utløsende faktorer for krybbedød i den typiske tre måneders alderen (1).

Imidlertid er det vanskelig å bestemme hvilke nyfødte som er intrauterint veksthemmet (9). Barn født til termin med normal fødselsvekt, kan godt være veksthemmet i forhold til deres "indre" vekstpotensiale. En måte å identifisere et spedbarns vekstpotensiale, er å sammenligne dets fødselsvekt med vekten til søsknene (3), fordi mødre har en tendens til føde barn med omtrent samme vekt $(10,11)$.

Vi undersøkte det intrauterine vekstpotensialet hos barn som senere døde i krybbedød med data fra Medisinsk fødselsregister. Vi hadde følgende hypotese: Krybbedøde har mindre fødselsvekt enn søsken som overlever første leveår. Fødselsvekt til krybbedødes søsken er nødvendigvis ikke representative for populasjonen. Derfor ble også fødselsvekt sammenlignet med søskenflokker uten spedbarnsdødsfall.

\section{MATERIALE OG METODE}

Alle fødsler fra 16. svangerskapsuke skal meldes til Medisinsk fødselsregister (MFR). MFR blir rutinemessig oppdatert med Dødsårsaksregisteret i Statistisk sentralbyrå ved hjelp av fødselsnummeret.

I perioden 1967 til 1988 ble 1323505 fødsler registrert. Av disse overlevde 1241236 første leveuke. Fra fødselskohortene døde totalt 5447 barn i postperinatalperioden (7-364 dager), hvorav $1984 \mathrm{i}$ krybbedød (12).

Alle fødte ble koblet sammen i søskenflokker ved hjelp av morens fødselsnummer (11). Denne studien besto av 358339 mødre som fødte minst to barn hvor første barn ble født i 1967 eller senere.

I analysene brukte vi data på mødrenes første til fjerde barn. Mødre med flere enn fire barn, deltok med sine første fire barn. Disse søskensettene ble analysert hver for seg; søskenflokker med to eller flere barn, søskenflokker med tre eller flere barn og søskenflokker med fire eller flere barn. Søskensettene er ikke gjensidig ekskluderende, men nøstet i hverandre fordi mødre med mange barn kan være en spesiell høyrisikogruppe $(13,14)$.

Innenfor hvert søskensett ekskluderte vi søskenflokker dersom en av de aktuelle spedbarna var tvilling, var dødfødte eller død av annen årsak i første leveår, eller det var gjentatt krybbedød. Vi ekskluderte alle søskenflokker med dødfødsel eller annen dødsårsak fordi vi ville sammenligne krybbedød med andre barn som kunne ha dødd i krybbedød. Tabell 1 viser antall søskenflokker som ble analysert.
TABLE 1. Number of sibships with $\geq 2, \geq 3$, or $\geq 4$ births, in sibships where all births survived the first year of life and in sibships with sudden infant death syndrome (SIDS): Norway, 1967-1988

\begin{tabular}{lrrr}
\hline & \multicolumn{3}{c}{ Sibships with } \\
\cline { 2 - 4 } & 22 births & 23 births & 24 births \\
\hline All alive & 357,207 & 113,853 & 20,769 \\
SIDS in first birth & 455 & 265 & 68 \\
SIDS in second birth & 677 & 533 & 176 \\
SIDS in third birth & & 255 & 176 \\
SIDS in fourth birth & & & 53 \\
Total & 358,339 & 114,906 & 21,242 \\
\hline
\end{tabular}

Gjennomsnittlig fødselsvekt og svangerskapslengde ble utregnet for hver paritet, fra første til fjerde barn i alle søskensettene. Svangerskapslengden ble utregnet fra siste menstruasjons første dag. Vi ekskluderte fødsler (ikke søskenflokker) hvis det manglet opplysninger om fødselsvekt $(0,3 \%)$ eller gestasjonsalder $(5,0 \%)$.

Deretter beregnet vi, for hver paritet, gjennomsnittlig fødselsvekt for krybbedøde, krybbedødes søsken, samt spedbarna i søskenflokker uten dødsfall på tvers av alle søskensettene. Hvert barn ble talt bare en gang. Disse gjennomsnittlige fødselsvektene for krybbedøde, deres søsken, og barn fra søskenflokker uten dødsfall, ble så sammenlignet med fødselsvekter standardisert for svangerskapslengde. Vi brukte direkte standardisering for å justere fødselsvektene mellom krybbedøde, deres søsken og barn fra søskenflokker uten dødsfall, slik at en eventuell forskjell i svangerskapslengde ble tatt vekk når vi skulle sammenligne fødselsvekten mellom krybbedøde, deres søsken og barn fra søskenflokker uten døde. Standardpopulasjonen var svangerskapsdistribusjonen oppgitt i uker, for barn av en gitt paritet i søskenflokker hvor alle barna overlevde første leveår.

\section{RESULTATER}

I søskenflokker med to eller flere fødte hvor begge overlevde første leveår, økte fødselsvekten fra 3447 til $3583 \mathrm{~g}$ fra første- til andrefødte, en økning på 136 g (figur 1). Fødselsvekten økte også fra første til andre barn i søskenflokker med krybbedød. Imidlertid var de krybbedøde mye mindre enn barn av samme paritet i søskenflokker uten dødsfall. Førstefødte som senere døde, veide $166 \mathrm{~g}$ mindre, og andrefødte som senere døde, veide $199 \mathrm{~g}$ mindre. I tillegg var krybbedødes søsken også lettere enn barn av samme paritet $\mathrm{i}$ søskenflokker uten dødsfall. Førstefødte med dødsfall blant andrefødte, veide $81 \mathrm{~g}$ mindre, og andre barn født etter en krybbedød, veide $79 \mathrm{~g}$ mindre.

De samme tre effektene på fødselsvekt var også til stede i søskenflokker med tre eller flere fødsler (figur 1). For det første, fødselsvekten øker med økende 

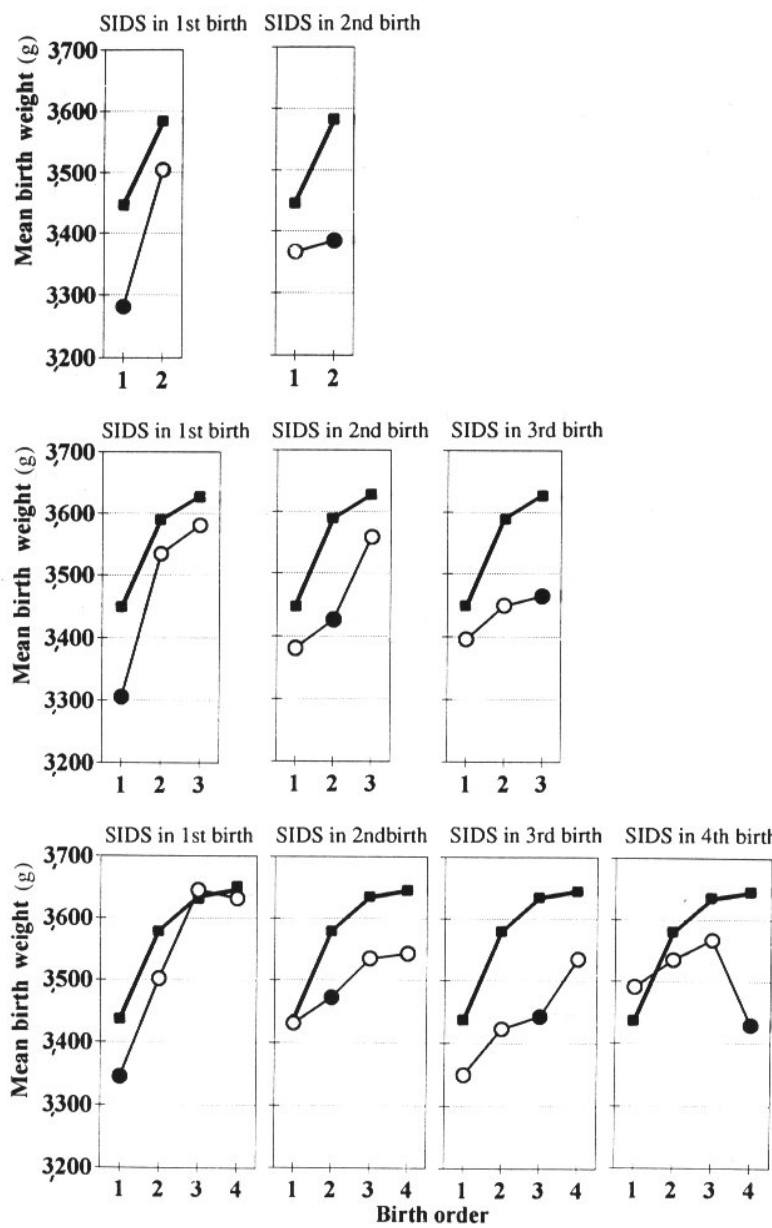

Figur 1. Gjennomsnittlig fødselsvekt i søskenflokker med to eller flere fødsler, søskenflokker med tre eller flere fødsler, og søskenflokker med fire eller flere fødsler, for hver paritet. Medisinsk fødselsregister, Norge 1967-1988. Symboler: Barn i søskenflokker uten spedbarnsdødsfall (ם), barn i søskenflokker med krybbedød (O), og deres søsken som overlever første leveår $(\mathrm{O})$.

paritet. I søskenflokker uten dødsfall, var økningen $142 \mathrm{~g}$ fra første til andre, og $38 \mathrm{~g}$ fra andre til tredje barn. For det andre, krybbedøde hadde mye lavere fødselsvekt. Vektdifferansen mellom krybbedøde og barn av samme paritet i søskenflokker uten dødsfall, var $142 \mathrm{~g}, 164 \mathrm{~g}$, og $164 \mathrm{~g}$ for henholdsvis første, andre og tredje barn. Og for det tredje, krybbedødes søsken hadde lavere fødselsvekt enn barn i søskenflokker uten dødsfall.

I søskenflokker med fire eller flere barn, var alle disse tre effektene på fødselsvekt også tydelige (figur 1).

Alle tre søskensettene viste det samme mønstret i fødselsvekt. Derfor tok vi, for hver paritet, gjennomsnittet av fødselsvekten for krybbedøde, søsken av krybbedøde, og barn fra søskenflokker uten dødsfall (tabell 2, figur 2). Fødselsvektsdistribusjonen for disse tre fødslene var klokkeformete og nærmest identiske når de ble lagt oppå hverandre. Distribusjonskurvene for krybbedøde og deres søsken var imidlertid venstreforskjøvet i forhold til kurven for barn fra søskenflokker uten dødsfall. Standardavviket for krybbedøde var bredest fordi distribusjonskurven var løftet noe i venstre hale (residual) (15).

Tilsvarende analyser ble gjort for svangerskapslengde. Gjennomsnittlig svangerskapslengde gikk litt ned med økende paritet i søskenflokker uten dødsfall. I søskenflokker med to eller flere barn, var svangerskapslengden 283.2 og 282.9 dager. I søskenflokker med tre eller flere barn, varte svangerskapet 283.5, 283.3, og 282.5 dager. Og i søskenflokker med fire eller flere barn, ble barna født etter 283.4, 283.4, 283.2, og 281.6 dager.

Det var ikke redusert svangerskapslengde for krybbedødes søsken sammenlignet med barn fra søskenflokker uten dødsfall. Imidlertid fant vi at krybbedøde hadde kortere svangerskap sammenlignet

TABLE 2. Mean birth weights and pooled standard deviations for infants in sibships where all survived, survivors in sibships with sudden infant death syndrome (SIDS), and SIDS infants, across sibships by birth order: Norway, 1967-1988

\begin{tabular}{rlrr}
\hline $\begin{array}{c}\text { Birth } \\
\text { order }\end{array}$ & \multicolumn{1}{c}{$\begin{array}{c}\text { Type of } \\
\text { birth }\end{array}$} & \multicolumn{1}{c}{ No. } & \multicolumn{1}{c}{$\begin{array}{c}\text { Mean birth } \\
\text { weight }(g)\end{array}$} \\
\hline First & All alive & 352,117 & $3,447(512.0) *$ \\
& Survivor & 939 & $3,376(538.6)$ \\
& SIDS & 432 & $3,294(612.8)$ \\
Second & All alive & 352,197 & $3,583(521.3)$ \\
& Survivor & 731 & $3,481(547.4)$ \\
& SIDS & 643 & $3,378(587.3)$ \\
Third & All alive & 112,533 & $3,629(541.5)$ \\
& Survivor & 842 & $3,564(540.0)$ \\
& SIDS & 240 & $3,468(621.4)$ \\
Fourth & All alive & 20,234 & $3,646(565.0)$ \\
& Survivor & 416 & $3,539(561.3)$ \\
& SIDS & 48 & $3,464(693.2)$ \\
\hline
\end{tabular}

* Numbers in parentheses, standard deviation.

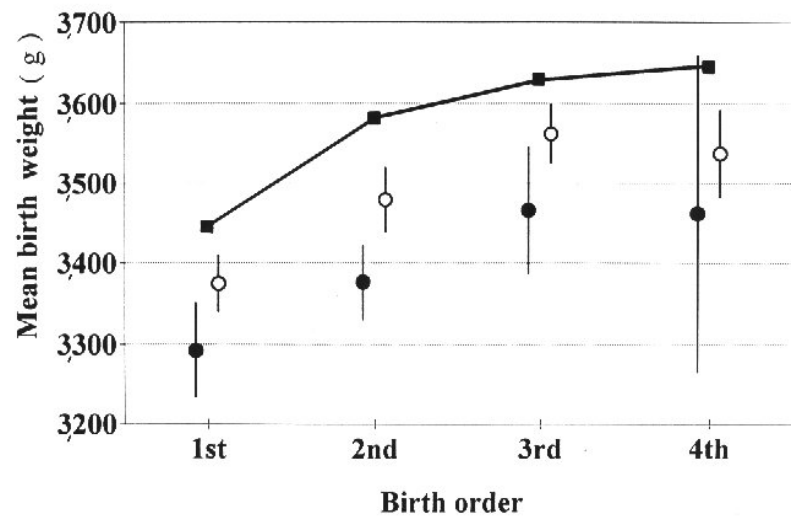

Figur 2. Gjennomsnittlig fødselsvekt for barn i søskenflokker uten spedbarnsdødsfall ( $\mathbf{\square})$, overlevende søsken av krybbedøde (O), og krybbedøde (O), for hver paritet. 95\% konfidensintervall inntegnet. Medisinsk fødselsregister, Norge 1967-1988. 
med søskenflokker uten dødsfall, uavhengig av paritet. I søskenflokker med to eller flere barn, var forskjellene $3.4 \mathrm{og} 2.7$ dager for første og andre fødte. I søskenflokker med tre eller flere barn, var forskjellene 2.1, 2.4, og 2.1 dager for første, andre, og tredje barn. Og i søskenflokker med fire eller flere barn, var forskjellene 1.0, 1.9, 2.3, og 3.7 dager. Den kortere svangerskapslengden hos krybbedøde skyldtes hovedsakelig at distribusjonskurven for svangerskapslengden var venstreforskjøvet, men også her var venstre hale noe løftet.

Denne kortere svangerskapslengden for krybbedøde kunne muligens forklare den lavere fødselsvekten hos krybbedøde (tabell 2, figur 2). Derfor standardiserte vi alle fødselsvektene til den samme svangerskapsdistribusjonen (figur 3). Standardiseringen tok vekk mesteparten av vektdifferansen mellom krybbedøde og deres søsken, mens differansen mellom krybbedødes søsken og barn fra søskenflokker uten dødsfall endret seg lite. Selv om vi justerte for svangerskapslengde, hadde barn fra søskenflokker med krybbedød gjennomgående lavere fødselsvekt.

Figur 4 oppsummerer vektdifferansene før og etter standardisering for svangerskapslengde. For hver paritet, tok vi gjennomsnittet av differansene mellom krybbedøde, krybbedødes søsken, og barn i søskenflokker uten dødsfall.

\section{DISKUSJON}

Vi fant at mødre til barn som senere dør i krybbedød, føder alle sine barn med gjennomsnittlig lavere fødselsvekt, men det er kun barnet som dør i krybbedød som ble født for tidlig.

Studien viste at barn i søskenflokker med krybbedød (både krybbedøde og søsken) er intrauterint veksthemmet sammenlignet med søskenflokker uten dødsfall. Denne veksthemningen kan tyde på en felles maternell faktor eller et felles maternelt miljø som påvirker alle svangerskapene hennes. En sannsynlig medvirkende faktor, er røyking i svangerskapet. Røyking i svangerskapet forskyver distribusjonskurven for fødselsvekt $200 \mathrm{~g}$ mot venstre (16). Og mødre som røyker i ett svangerskap, røyker sannsynligvis i alle svangerskap.

En felles maternell faktor kan muligens øke risikoen for gjentatt krybbedød i søskenflokker. Relativ risiko for gjentatt krybbedød er 5,9 (95\% KI 2,514,1), basert på analyser fra MFR (17). Patofysiologiske studier har vist at søsken av krybbedøde har forstyrret hjerte- og respirasjonsaktivitet, som er avhengig av postnatal alder og søvnstadium (18).

Barnet som senere døde i krybbedød hadde tilleggsfaktorer ved fødselen. Kortere svangerskapslengde og ytterligere veksthemning karakteriserte de krybbedøde $\mathrm{i}$ forhold til overlevende søsken av krybbedøde. Kortere svangerskap kan virke inn på flere måter. Kortere svangerskap kan øke risikoen for krybbedød fordi barnet er for umodent til å mestre postnatale faktorer som kan bidra til døden (4). I den nordiske epidemiologiske krybbedødstudien fant vi at den kombinerte effekten av for tidlig fødsel og mageleie hadde en relativ risiko på 50 (95\% KI 19103) sammenlignet med barn født til termin som ble lagt til å sove på ryggen (Øyen et al., upublisert).

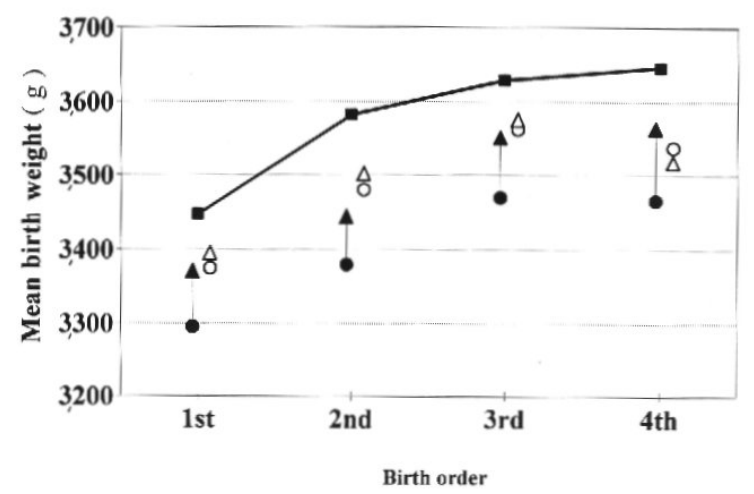

Figur 3. Gjennomsnittlig fødselsvekt, ujusterte og justerte for svangerskapslengde, for hver paritet. Medisinsk fødselsregister, Norge 1967-1988.

Symboler: Barn i søskenflokker uten spedbarnsdødsfall $(\square)$, barn i søskenflokker med krybbedød, ujustert $(\mathbf{O})$ og justert $(\boldsymbol{\Delta})$, og deres søsken som overlever første leveår, ujustert $(\mathrm{O})$ og justert (åpen trekant).

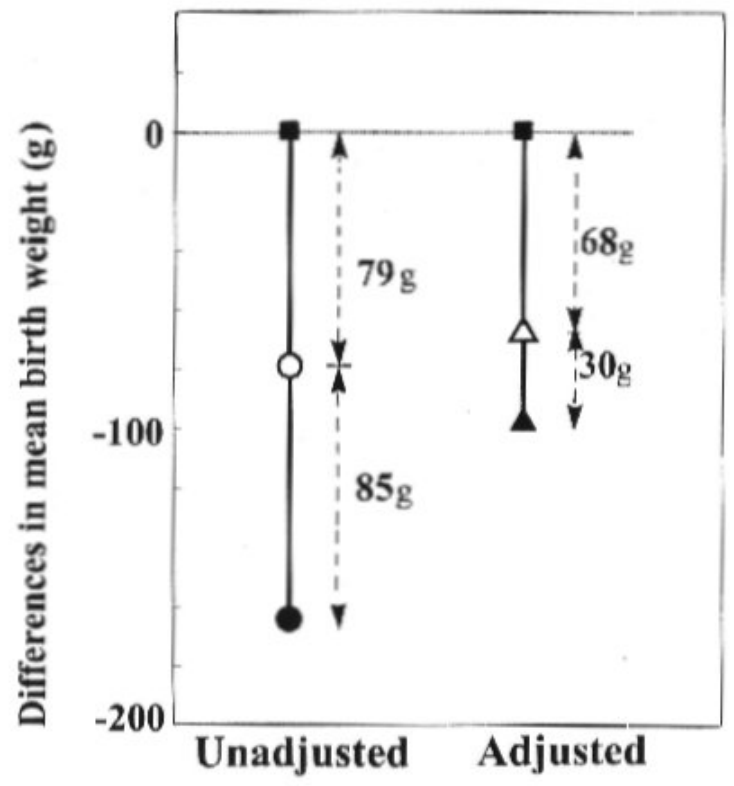

Figur 4. Differanser mellom fødselsvekt for krybbedøde og deres søsken, og mellom krybbedødes søsken og barn i søskenflokker uten dødsfall, utregnet over alle pariteter, før og etter justering for svangerskapslengde. Medisinsk fødselsregister, Norge 1967-1988.

Symboler: Barn i søskenflokker uten spedbarnsdødsfall (ם), barn i søskenflokker med krybbedød, ujustert (О) og justert $(\boldsymbol{\Delta})$, og deres søsken som overlever første leveår, ujustert $(\mathrm{O})$ og justert (åpen trekant). 
På den annen side, kortere svangerskap kan være et resultat av andre svangerskapsrelaterte faktorer som både gir for tidlig fødsel og øker risikoen for krybbedød. Denne faktoren er sannsynligvis forskjellig fra de tilstandene som gir gjentatt preterm fødsel (19). En infeksjon i det aktuelle svangerskapet kan være et eksempel på en faktor som både er assosiert med for tidlig fødsel $(16,20)$ og økt risiko for krybbedød (6). En infeksjon kan også virke forsterkende dersom den felles maternelle faktoren er tilstede, som for eksempel røyking.

Barn i søskenflokker hvor ett av barna døde i krybbedød har, uavhengig av svangerskapslengde, gjennomsnittlig lavere fødselsvekt. Barnet som døde, er for hver svangerskapsuke, enda mindre enn sine søsken, fordi de har kortere svangerskap, samt at de er ytterligere veksthemmet. Den lavere fødselsvekten hos både krybbedøde og deres søsken kan skyldes felles faktorer som kan bidra til krybbedød, slik som røyking i svangerskapet. De faktorene som gir kortere svangerskap og ytterligere intrauterin veksthemning hos krybbedøde, er viktige å påvise. Det kan se ut som om disse svangerskapsfaktorene virker på barnet som senere døde i krybbedød, men ikke på søsknene.

\section{EPILOG}

Hadde MFR registrert mors røykevaner i svangerskapet, kunne vi forsatt studien med følgende hypotese: Barn i søskenflokker der et av barna døde i krybbedød, har lettere fødselsvekt, fordi mor røykte i svangerskapene, mens den enda lavere fødselsvekten hos barnet som senere døde i krybbedød kan ikke forklares med mors røyking.

Imidlertid har Medisinsk fødselsregister i Sverige registrert mors røykevaner siden 1983. Derfor har vi samarbeidet med Bengt Haglund ved Epidemiologisk Center, Socialstyrelsen, Stockholm, og analysert svenske søskenfiler med opplysninger om mors røykevaner ved første gangs svangerskapskontroll. Vi analyserte søskenfilene ved hjelp av repeated measures analysis of variance (ANOVA) hvor mor var analyseenheten, og fødselsvekt og gestasjonsalder på barna hennes var den repeterte måling. Denne spennende oppfølgningen av studien publiseres i januar 1997 (21).

Takk til Lorentz M. Irgens for gjennomlesning av manuskriptet.

\section{REFERANSER}

1. Little RE, Peterson DR. Sudden infant death syndrome epidemiology: A review and update. Epidemiol Rev 1990; 12: 241-6.

2. Valdes Dapena M. Sudden infant death syndrome. Morphology update for forensic pathologists 1985. Forensic Sci Int 1986; 30: 177-86.

3. VanBelle G, Hoffman HJ, Peterson DR. Intrauterine growth retardation and the sudden infant death syndrome. In: Harper RM, Hoffman HJ, editors. Sudden infant death syndrome. Risk factors and basic mechanisms. New York: PMA Publishing Corp, 1988: 203-19.

4. Southall DP. Role of apnoea in the sudden infant death syndrome: A personal view. Pediatrics 1988; 81: 7384.

5. Buck GM, Cookfair DL, Michalek AM, et al. Intrauterine growth retardation and risk of sudden infant death syndrome (SIDS). Am J Epidemiol 1989; 129: 874-84.

6. Buck GM, Cookfair DL, Michalek AM, et al. Assessment of in utero hypoxia and risk of sudden infant death syndrome. Paediatr Perinat Epidemiol 1989; 3: 157-73.

7. Kinney HC, Brody BA, Finkelstein DM, et al. Delayed central nervous system myelination in the sudden infant death syndrome. J Neuropathol Exp Neurol 1991; 50: 29-48.

8. Hinchliffe SA, Howard CV, Lynch MR, et al. Renal developmental arrest in sudden infant death syndrome. Pediatr Pathol 1993; 13: 333-43.

9. Wilcox AJ. Intrauterine growth retardation: beyond birth weight criteria (editorial). Early Human Development 1983; 8: 189-93.

10. Bakketeig LS, Hoffman HJ. The tendency to repeat gestational age and birth weight in successive births, related to perinatal survival. Acta Obstet Gynecol Scand 1983; 62: 385-92.

11. Skjærven R, Wilcox AJ, Russell D. Birth weight and perinatal mortality of second births conditional on weight of the first. Int J Epidemiol 1988; 17: 830-8.

12. Øyen N, Irgens LM, Skjærven R, et al. Secular trends of sudden infant death syndrome in Norway, $1967-$ 1988. Application of a method of case identification to Norwegian registry data. Paediatr Perinat Epidemiol 1994; 8: 263-81. 
13. Golding J. The epidemiology of perinatal death. In: Kiely M, editor. Reproductive and perinatal epidemiology. Boca Raton: CRC Press, 1991: 401-36.

14. Skjærven R, Wilcox AJ, Lie RT, et al. Selective fertility and the distortion of perinatal mortality. Am $J$ Epidemiol 1988; 128: 1352-63.

17. Wilcox AJ, Russell IT. Birth weight and perinatal mortality: III. Towards a new method of analysis. Int $J$ Epidemiol 1986; 15: 188-196.

16. Kline J, Stein Z, Susser M. Conception to birth. Epidemiology of prenatal development. New York: Oxford University Press, 1989: 214, 203-4.

17. Øyen N, Skjærven R, Irgens LM. Population-based recurrence risk of sudden infant death syndrome compared with other infant and fetal deaths. Am J Epidemiol 1996; 144: 300-5.

18. Harper RM, Frysinger RC. Suprapontine mechanisms underlying cardiorespiratory regulation: Implications for the sudden infant death syndrome. In: Harper RM, Hoffman HJ, editors. Sudden infant death syndrome. Risk factors and basic mechanisms. New York: PMA Publishing Corp, 1988: 399-412.

19. Bakketeig LS, Hoffman HJ. The tendency to repeat ges tational age and birth weight in successive births. Am J Obstet Gynecol 1979; 135: 1086-1103.

20. Schieve LA, Handler A, Hershow R, et al. Urinary tract infection during pregnancy: Its association with maternal morbidity and perinatal outcome. Am J Public Health 1994; 84: 405-10.

21. Øyen N, Haglund B, Skjærven R, Irgens LM. Maternal smoking, birthweight and gestational age in sudden infant death syndrome (SIDS) babies and their surviving siblings. Paediatr Perinat Epidemiol 1997 (in press). 